\title{
Neuroimaging findings in a woman with brainstem paragonimiasis: a case report and review of the literature
}

\author{
Dong Yi, Dong Qiang and Cao Wenjie*
}

\begin{abstract}
Introduction: The most serious erratic migration of paragonimiasis is a cerebral paragonimiasis. Infection in the temporal and occipital lobes of the brain has been previously reported in cerebral paragonimiasis. Here, we report a case of chronic brainstem paragonimiasis.

Case presentation: A 29-year-old Chinese woman presented to our hospital complaining of a sudden onset, three days previously, of double vision and dizziness. A computed tomography scan and diffusion-weighted images looked like an ischemic stroke. However, conglomerates of multiple ring-like enhancements on contrast magnetic resonance imaging, and the characteristic appearance of the 'tunnel sign', were found on further examination. Our patient was treated with praziquantel to prevent the spread of the paragonimiasis. She was followed up three months later and showed good recovery.
\end{abstract}

Conclusions: Conglomerates of multiple ring-like enhancements on contrast magnetic resonance imaging and the characteristic appearance of the 'tunnel sign' were important for the diagnosis of chronic brainstem paragonimiasis.

Keywords: Neuroimaging, Brainstem, Paragonimiasis

\section{Introduction}

Paragonimiasis is an infection by the genus Paragonimus, the most common of which is Paragonimus Westermani. P. Westermani is a common human parasite in the Far East, and is particularly prevalent in China, Japan, and Korea. Paragonimiasis results from the ingestion of raw or insufficiently cooked second intermediate hosts such as freshwater crayfish, crabs, or shrimp. The metacercariae excyst in the small intestine penetrate the wall into the abdominal cavity, which then migrate through the viscera and diaphragm to the lungs. The lung is the principal habitat in the human host. The erratic migrations of the juvenile flukes result in ectopic paragonimiasis in various organs, frequently in the peritoneal and pelvic cavities, the diaphragm, the subcutaneous tissues, and the brain [1,2]. The most serious erratic migration is a cerebral paragonimiasis, where the fluke enters the cranial cavity through the jugular or carotid foramen, and usually invades the

\footnotetext{
* Correspondence: caowenjiefb@gmail.com

The Department of Neurology, Huashan Hospital, Fudan University, No. 12 Wulumuqi Zhong Rd., 200040 Shanghai, P.R. China
}

brain. Infection of temporal and occipital lobes of the brain has been reported [2-5]. Cerebral paragonimiasis is serious and sometimes fatal, although symptoms of ectopic infections are solely dependent on the infected sites and the number of parasites. Here, we report a case of a chronic cerebral paragonimiasis in the brainstem with a sudden onset.

\section{Case presentation}

A 29-year-old Chinese woman presented to our hospital with a sudden onset, three days previously, of double vision and a feeling of dizziness. She had vomited twice without seizures or unconsciousness. During her physical and neurological examination, a twist in her tongue and diplopia were observed. Our patient was born near an endemic area of paragonimiasis and used to eat grilled freshwater crab. The laboratory results of her blood test were: red blood cell count $4.08 \times 10^{12} / \mathrm{L}$, white blood cell count $4.08 \times 10^{9} / \mathrm{L}$ (neutrophils $54.8 \%$, lymphocytes $38.2 \%$, monocytes $5.6 \%$, eosinophils $1.2 \%$, basophils $0.2 \%$ ), hemoglobin $134 \mathrm{~g} / \mathrm{L}$ and platelet count $175 \times 10^{9} / \mathrm{L}$. An examination of her fecal specimens 
was negative and her chest radiography was normal. An emergency computed tomography (CT) scan showed a suspect low-density lesion in the brainstem with no abnormal calcification. Our patient was diagnosed as having had an ischemic stroke and treated with aspirin. However, a magnetic resonance imaging (MRI) scan of her brain revealed an egg-like lesion in her brainstem, with a slight hyperintensity on both $\mathrm{T} 1$ and T2, and conglomerates of multiple ring-like enhancements on contrast MRI (Figure 1). The MRI scan also revealed an abnormal signal on the lateral angles. The characteristic appearance of paragonimiasis is the 'tunnel sign', which shows the track of the adult worm (Figure 2). The result of a protein test of her cerebrospinal fluid was $339 \mathrm{mg} / \mathrm{L}$. The results of an enzyme-linked immunosorbent assay for Westermani were highly positive. Since there was no change in her blood test and no edema around the lesion, it was presumed that $P$. Westermani had formed the brain lesions a long time ago. Praziquantel $(25 \mathrm{mg} / \mathrm{kg}$ three times a day) was prescribed to prevent the spread of the paragonimiasis. Our patient was followed up three months later, there was no progression of the lesions, and the symptoms had disappeared.

\section{Discussion}

The frequency of cerebral involvement has been reported in 20 to $45 \%$ of patients with erratic paragonimiasis [6]. In a recently reported case, $3.5 \%$ of patients with food-borne parasitic encephalopathy were due to cerebral paragonimiasis. In hospital-based studies, $0.8 \%$ of the positive reactions in intradermal tests for Paragonimus are compatible with a cerebral paragonimiasis [7]. Cerebral paragonimiasis is diagnosed by radiological findings, as well as by immunologic and parasitology methods. Nomura et al. reported four pathological stages of the cerebral parasite. Briefly, stage I consisted of apparently viable cysts surrounded by a thin layer of collagen type I. In stage II, a mononuclear-rich inflammatory infiltrate became evident around the parasite. At stage III, granulomas with associated inflammatory infiltrates and fibrosis were formed, and an abundant number of eosinophils had migrated to the center of the lesion, to be located between the parasite and granuloma. By stage IV the same cell types were evident, but the center of the lesion contained the disintegrated parasite and amorphous material reminiscent of necrosis [8]. This granulomatous response in swine resembled previous findings in humans, but differed in the

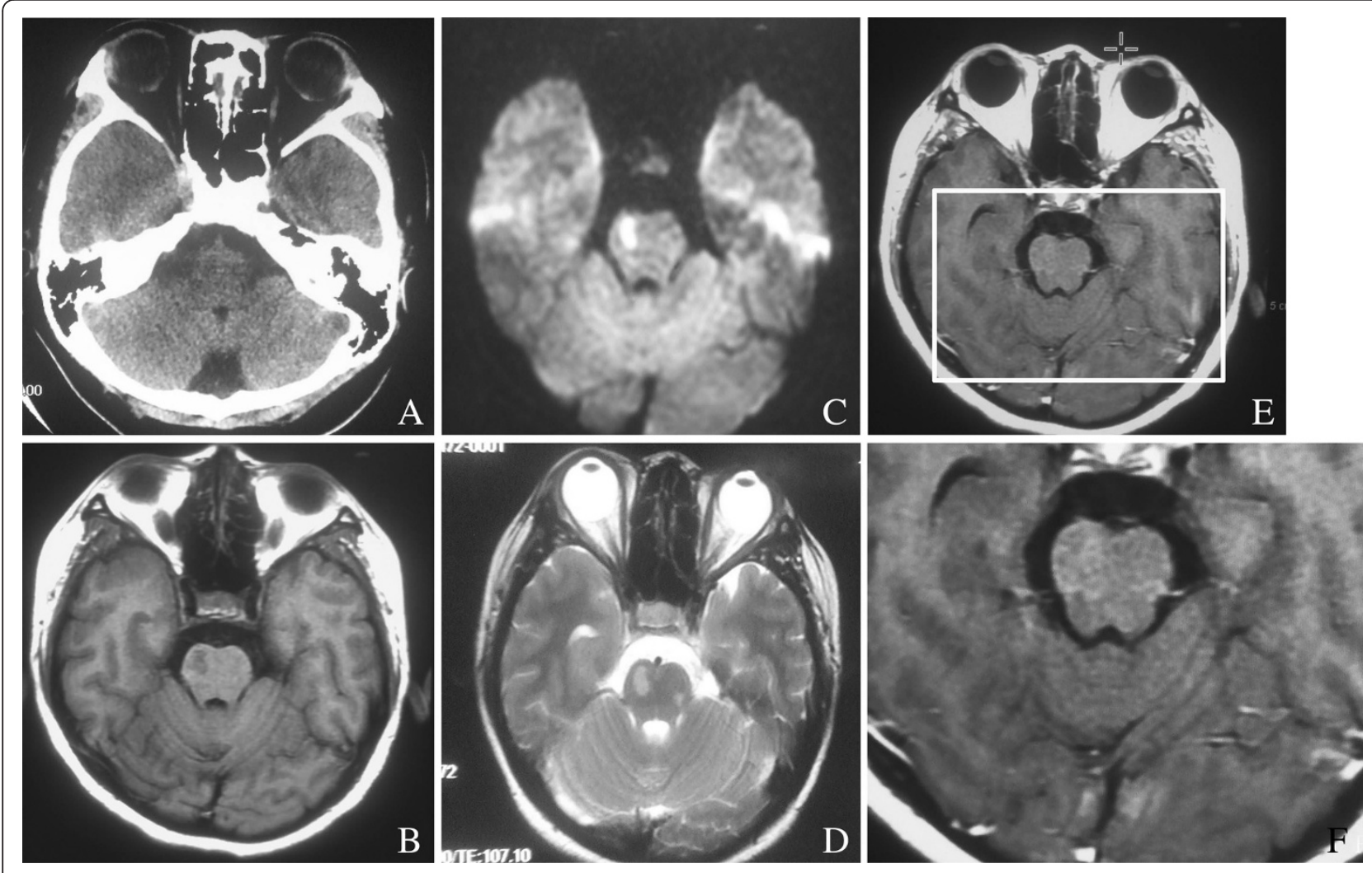

Figure 1 (A) A suspect low-density lesion in the brainstem with no abnormal calcification. (B-F) A brain magnetic resonance imaging scan revealed an egg-like lesion in the brainstem, with a slight hyperintensity in $\mathrm{T} 1$, hyperintensity in $\mathrm{T} 2$ and DWI, and conglomerates of multiple ring-like enhancements in contrast magnetic resonance imaging. 

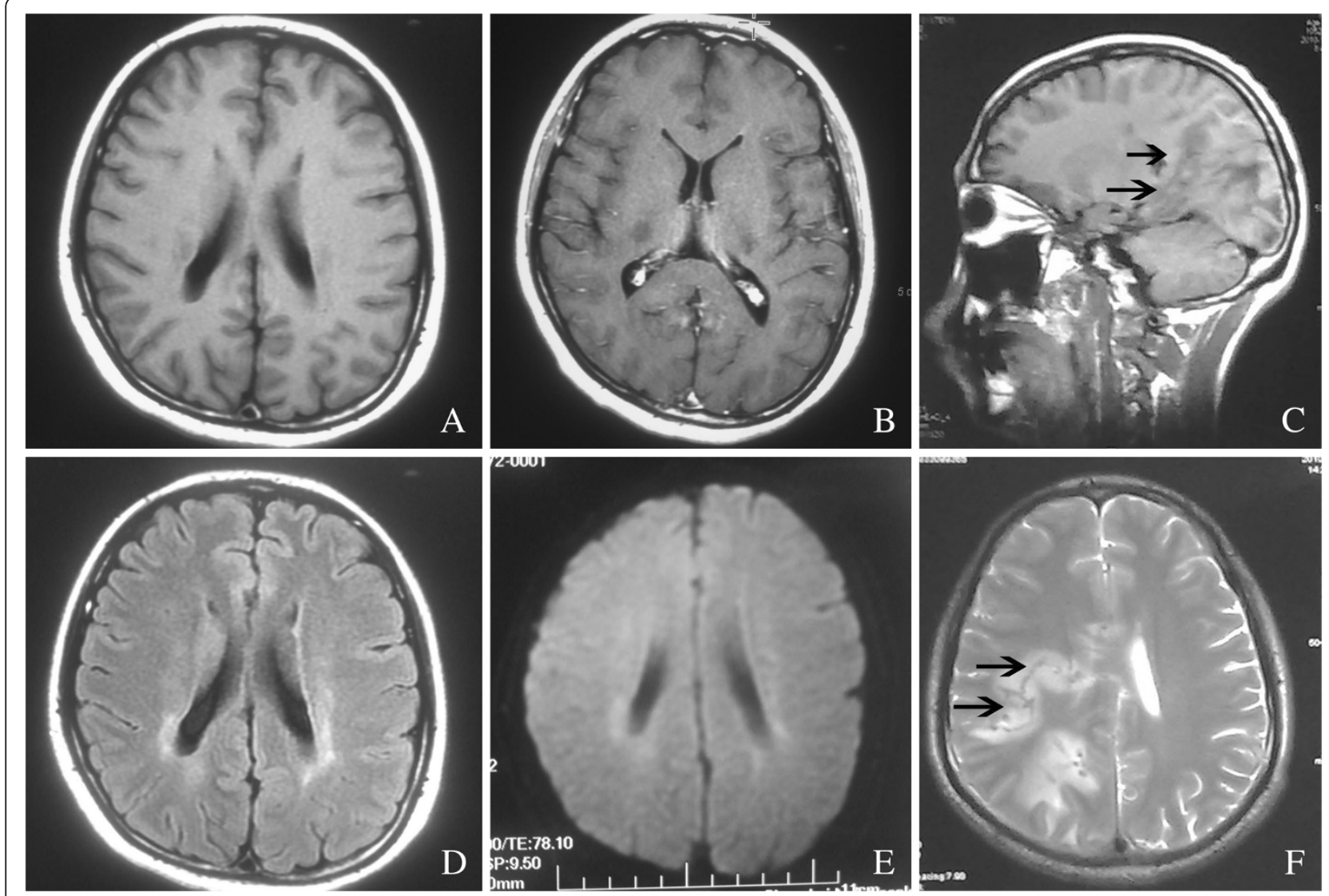

Figure 2 An abnormal sign on the lateral angles on the magnetic resonance imaging scan. The characteristic appearance was the 'tunnel sign', which was arrowed in T1 sagittal (C) and T2 axial sequences (F). FLAIR imaging (D) indicated leukoencephalopathy on the lateral angles. However, there were no remarkable changes on T1 (A), contrasted MR (B) and DWI imaging (E).

abundance of eosinophils, the presence of fewer plasma cells and discrete deposition of collagen. These variations may be partly attributed to an immune response that is detected earlier in swine, but at a more chronic stage in humans. The CT and MRI findings for chronic cerebral paragonimiasis have been generally recorded as conglomerates of multiple ring-shaped shadows or enhancements of 'grape cluster' or 'soap bubble' forms in one hemisphere $[3,4,8,9]$. The present case showed typical radiology findings of chronic paragonimiasis such as multiple conglomerated round calcified nodules in the brainstem, which has not been reported. An enzyme-linked immunosorbent assay (ELISA) is recommended as a complementary tool for diagnosing cerebral paragonimiasis, and the serum and ELISA antibody levels are generally positive in $48 \%$ and $31 \%$ of chronic cases, respectively [3]. In our case, the ELISA results for the diagnosis of paragonimiasis were positive and there were many $P$. Westermani eggs in the worm capsules resected from the patients' brain. Numerous $P$. Westermani eggs were well preserved and were also present in the tunnel sign, which showed the track of the adult worm. In addition, most of the eggs in the worm capsules retained a shell without a yolk. This indicates that the worm capsules in the brain had been established a long time ago, as adult worms die within 10 to 20 years, even without treatment [9]. In addition, the worm capsules remain as multiple nodules with a low-density cavity containing the Paragonimus eggs in cases of cerebral paragonimiasis that persist for more than 20 years $[1,9]$.

\section{Conclusions}

Our patient had a sudden onset of a chronic cerebral paragonimiasis infection. The CT scan and diffusionweighted images resembled an ischemic stroke in the brainstem. However, conglomerates of multiple ring-like enhancements on contrast MRI, and the characteristic appearance of the 'tunnel sign', were important for diagnosis.

\section{Consent}

Written informed consent was obtained from the patient for publication of this manuscript and any accompanying images. A copy of the written consent is available for review by the Editor-in-Chief of this journal. 


\section{Abbreviations}

CSF: Cerebrospinal fluid; CT: Computed tomography; DWI: Diffusion-

weighted images; ELISA: Enzyme-linked immunosorbent assay; MRI: Magnetic resonance imaging; FLAIR: Fluid attenuated inversion recovery.

\section{Competing interests}

The authors declare that they have no competing interests.

\section{Authors' contributions}

DY analyzed and interpreted the patient data and was a major contributor in writing the manuscript. CWJ performed the neuroimaging explanation of the cerebral lesions and helped to interpret the patient data. DQ designed and organized the study. All authors have read and approved the final manuscript.

Received: 17 June 2013 Accepted: 12 November 2013

Published: 5 February 2014

\section{References}

1. Bunnay D, Cross JH, Bunnay T: Lung fluke infections; paragonimiasis. In Hunter's tropical medicine and emerging infectious diseases. Eighthth edition. Edited by Strickland GT. Philadelphia: W. B. Saunders Company; 2000:847-851.

2. Cho SY: Epidemiology of paragonimiasis in Korea. In Collected papers on parasite control in Korea. Edited by Chai JY, Cho SY, Han IS, Lee SH, Rim HJ. Seoul, Korea: The Korea Association of Health; 1994:51-57.

3. Chang KH, Cha SH, Han MH, Kim HD, Cho SY, Kong Y, Kang HK, Kim MS: An imaging diagnosis of cerebral paragonimiasis: $C T$ and MR findings and correlation with ELISA antibody test. J Korean Radio/ Soc 1993, 29:345-354.

4. Cha SH, Chang KH, Cho SY, Han MH, Kong Y, Suh DC, Choi CG, Kang HK, Kim MS: Cerebral paragonimiasis in early active stage: $\mathrm{CT}$ and MR features. AJR Am J Roentgenol 1994, 162:141-145.

5. Choo JD, Suh BS, Lee HS, Lee JS, Song CJ, Shin DW, Lee YH: Chronic cerebral paragonimiasis combined with aneurysmal subarachnoid hemorrhage. Am J Trop Med Hyg 2003, 69:466-469.

6. Beers MH, Berkow R: The Merck manual of diagnosis and therapy. 17th edition. Merck Research Laboratories: Rahway, NJ; 2002.

7. Oh SJ: The rate of cerebral involvement in paragonimiasis: an epidemiologic study. Jpn J Parasitol 1969, 18:211-214.

8. Nomura M, Nitta H, Nakada M, Yamashima T, Yamashita J: MRI findings of cerebral paragonimiasis in chronic stage. Clin Radiol 1999, 54:622-624.

9. Kadota T, Ishikura R, Tabuchi Y, Nakao N, Fujikawa H, Kaba K, Tani E, Miura T: MR imaging of chronic cerebral paragonimiasis. AJNR 1989, 10:S21-S22.

doi:10.1186/1752-1947-8-36

Cite this article as: Yi et al:: Neuroimaging findings in a woman with brainstem paragonimiasis: a case report and review of the literature. Journal of Medical Case Reports 2014 8:36.

\section{Submit your next manuscript to BioMed Central and take full advantage of:}

- Convenient online submission

- Thorough peer review

- No space constraints or color figure charges

- Immediate publication on acceptance

- Inclusion in PubMed, CAS, Scopus and Google Scholar

- Research which is freely available for redistribution 